\title{
Impact of COVID-19 pandemic on the vitreoretinal service at St Thomas' Hospital, London
}

\author{
Neruban Kumaran ${ }^{1,2}$. Giancarlo Dell'Aversana Orabona ${ }^{1,3}$ - Philip J. Banerjee ${ }^{2} \cdot$ Tom H. Williamson $\mathbb{1}^{1,4}$. \\ David A. H. Laidlaw ${ }^{1,3,4} \cdot$ Roger Wong ${ }^{1,2,4}$
}

Received: 8 November 2020 / Revised: 16 November 2020 / Accepted: 27 November 2020 / Published online: 14 January 2021

(c) The Author(s), under exclusive licence to The Royal College of Ophthalmologists 2021

\section{To the Editor:}

We read with interest Wickham et al. and Dervenis et al.'s recent publications demonstrating an $\sim 60 \%$ decrease in the presentation of rhegmatogenous retinal detachment (RRD) at Moorfields Eye Hospital, London and St Paul's Eye Unit, Liverpool, during the Coronavirus disease 2019 (COVID-19) pandemic $[1,2]$.

We conducted a similar, retrospective analysis of RRD operations undertaken at St Thomas' Hospital, London, Frimley Park Hospital, Frimley and Maidstone Hospital, Maidstone between the 24 March 2020 and 24 April 2020 (inclusive) and compared this to a comparative cohort between the same dates in 2019 .

St Thomas' Hospital, London provides a tertiary referral service for patients with RRDs, including those with complex medical needs in London and the South East of England, utilising a hub-and-spoke model with Maidstone Hospital and Frimley Park Hospital for emergency vitreoretinal services, serving a combined population of 2.1 million patients.

Table 1 demonstrates the cohort characteristics in our study. A similar number of operations for RRD were undertaken during the COVID-19 pandemic $(n=33)$ and comparative $(n=29)$ cohorts, respectively. Notably, 19 operations were performed at St Thomas' Hospital, 8 at Frimley Park Hospital, and 6 at Maidstone Hospital during the pandemic.

Roger Wong

drrogerwong@gmail.com

1 St Thomas' Hospital, Guy's and St Thomas' NHS Foundation Trust, London, UK

2 Frimley Park Hospital, Frimley Health NHS Foundation Trust, Frimley, UK

3 Maidstone Hospital, Maidstone and Tunbridge Wells NHS Trust, Maidstone, UK

4 King's College Medical School, London, UK
During the comparative 2019 time period, only one surgery was performed at each Frimley Park Hospital and Maidstone Hospital, with all other operations performed at St Thomas' Hospital. During the pandemic, patients waited for a median of 1 day for surgery. We demonstrate an increased use of local anaesthetic $(p=0.01)$ during the pandemic, and comparable use of vitrectomy between cohorts.

Further similarities were noted in age $(p=0.32)$, extent of $\operatorname{RRD}(p=0.43)$ and presentation with fovea off $\operatorname{RRD}(p=$ 0.77 ) between the 2 groups. However worse visual acuity

Table 1 Cohort characteristics.

\begin{tabular}{|c|c|c|}
\hline & $\begin{array}{l}\text { COVID-19 } \\
\text { cohort }\end{array}$ & $\begin{array}{l}2019 \\
\text { Comparative cohort }\end{array}$ \\
\hline Number of patients & 33 & 29 \\
\hline Age (years), mean $( \pm \mathrm{SD})$ & $58.6( \pm 12.8)$ & $60.1( \pm 11.2)$ \\
\hline $\begin{array}{l}\text { Presenting visual acuity } \\
\text { (LogMAR), median (IQR) }\end{array}$ & $\begin{array}{l}1.00 \\
(0.10-2.30)\end{array}$ & $0.30(0.00-1.90)$ \\
\hline \multicolumn{3}{|l|}{ Fovea status, $n(\%)$} \\
\hline Fovea on & $17(52 \%)$ & $17(59 \%)$ \\
\hline Fovea off & $14(42 \%)$ & $12(41 \%)$ \\
\hline Not documented & $2(6 \%)$ & $0(0 \%)$ \\
\hline \multicolumn{3}{|l|}{ PVR grade, $n(\%)$} \\
\hline PVR B & $2(6 \%)$ & $2(7 \%)$ \\
\hline PVR C & $7(22 \%)$ & $0(0 \%)$ \\
\hline $\begin{array}{l}\text { Quadrants affected, } \\
\text { mean }( \pm \mathrm{SD})\end{array}$ & $2.20( \pm 1.30)$ & $2.25( \pm 0.84)$ \\
\hline Local anaesthetic, $n(\%)$ & $31(94 \%)$ & $20(69 \%)$ \\
\hline \multicolumn{3}{|l|}{ Operation } \\
\hline $\mathrm{PPV}, n(\%)$ & $31(94 \%)$ & $26(90 \%)$ \\
\hline PPV-SB, $n(\%)$ & $1(3 \%)$ & $1(3 \%)$ \\
\hline $\mathrm{SB}, n(\%)$ & $1(3 \%)$ & $2(7 \%)$ \\
\hline
\end{tabular}

Shown are the cohort characteristics for the COVID-19 cohort and comparative 2019 cohort.

$P V R$ Proliferative vitreoretinopathy, $P P V$ pars-plana vitrectomy, $P P V$ $S B$ combined pars plana vitrectomy and scleral buckle, $S B$ scleral buckle. 
$(p=0.02)$ and the presence of proliferative vitreoretinopathy $(p=0.01)$ were identified in the pandemic cohort.

We therefore suggest a consistent presentation of RRD during the COVID-19 pandemic. Changes in management include increased, efficient provision of care locally with judicious use of general anaesthetic. We feel that this highlights the importance and ability to provide an efficient vitreoretinal emergency service during a pandemic.

\section{Compliance with ethical standards}

Conflict of interest The authors declare that they have no conflict of interest.
Publisher's note Springer Nature remains neutral with regard to jurisdictional claims in published maps and institutional affiliations.

\section{References}

1. Wickham L, Hay G, Hamilton R, Wooding J, Tossounis H, da Cruz $\mathrm{L}$, et al. The impact of COVID policies on acute ophthalmology services-experiences from Moorfields Eye Hospital NHS Foundation Trust. Eye. 2020;34:1189-92.

2. Dervenis N, Heimann H, Hussain RN, Chua PY, Sandinha T, Vilà N, et al. The impact of COVID policies on the vitreoretinal service in St Paul's Eye Unit, Liverpool. Eye. 2020:1-2. 